\title{
Evaluating the efficacy of the Headsprout@ reading program with children who have spent time in care
}

Storey, C., McDowell, C., \& Leslie, J. (2017). Evaluating the efficacy of the Headsprout@ reading program with children who have spent time in care. Behavioral Interventions, 32(3), 285-293. https://doi.org/10.1002/bin.1476

Link to publication record in Ulster University Research Portal

\section{Published in:}

Behavioral Interventions

Publication Status:

Published (in print/issue): 09/07/2017

DOI:

https://doi.org/10.1002/bin.1476

\section{Document Version}

Publisher's PDF, also known as Version of record

\section{General rights}

Copyright for the publications made accessible via Ulster University's Research Portal is retained by the author(s) and / or other copyright owners and it is a condition of accessing these publications that users recognise and abide by the legal requirements associated with these rights.

\section{Take down policy}

The Research Portal is Ulster University's institutional repository that provides access to Ulster's research outputs. Every effort has been made to ensure that content in the Research Portal does not infringe any person's rights, or applicable UK laws. If you discover content in the Research Portal that you believe breaches copyright or violates any law, please contact pure-support@ulster.ac.uk. 


\title{
Evaluating the efficacy of the Headsprout $(\subset$ reading program with children who have spent time in care
}

\author{
Catherine Storey I Claire McDowell (D) I Julian C. Leslie (D)
}

School of Psychology, Ulster University, Coleraine, UK

\section{Correspondence}

Julian C. Leslie, School of Psychology, Ulster University, Cromore Road, Coleraine, BT52 1SA, UK.

Email: jc.leslie@ulster.ac.uk
This study investigated whether Headsprout(c), an internet-based phonics program designed on behavioral principles, is an effective supplementary tool to improve literacy skills of children who have spent time in care and are at risk of reading failure. Participants were 8 children (aged 5 to 10) who had spent over 3 years in care and were fully adopted at the time of the study. Participants' literacy skills were assessed prior to intervention using 2 standardized reading attainment tests. Participants were then randomly assigned to either treatment or a waiting list comparison group. There were 2 Headsprout $($ c treatments, but all participants in the treatment group completed 1 Headsprout $($ lesson 4 times per week, under the supervision of the first author, while participants in the comparison group interacted with the first author 4 times per week engaging in nonliteracy-based computer activities. Results from 2 standardized reading attainment tests showed an improvement in word recognition age and oral reading fluency for the Headsprout $(C)$ learners but scores either remained the same or decreased over a 4-month period for participants in the comparison group. The findings support the wider use of Headsprout(C) with atrisk children though more research is clearly warranted at this time.

\section{1 | INTRODUCTION}

Children in the care of the state ("looked-after children") and adopted children who earlier spent at least 1 year in the care of state services underperform academically (Department of Education, 2012). Some attention is now being paid to looked-after children in the UK, following the publication of Every Child Matters (2003) and the Children Act (2004). However, children who have been adopted are often overlooked (Dann, 2011) despite evidence that placement of these children in a stable familial environment does not always eradicate the impact of early life trauma, neglect, or abuse on developmental progress and educational achievement (Cairns, 2002).

This research was supported by a Research Studentship awarded to the first author by the Department for Employment and Learning, Northern Ireland. 
The education gap between children who have been in state care and their peers grows as children progress through the education system. At age 14, only 34\% of looked-after children achieved their English curriculum targets compared with $79 \%$ of the general school population (Department of Education, 2012). As a result, they are likely to struggle throughout their academic experience (Francis, Shaywitz, Stuebing, Shaywitz, \& Fletcher, 1996). Children who fail to achieve basic literacy skills by age 11 have a greater likelihood of later being classified as adults with low basic skills, and this is linked to negative life outcomes such as unemployment (Department for Education and Employment, 1999).

The strongest predictors of reading and spelling ability are phonemic awareness (segmentation and blending of phonemes that make up a word) and letter-sound correspondence (Davidson \& Jenkins, 1994). Even though research shows the importance of explicit, systematic teaching of phonics and phonological awareness (Johnston \& Watson, 2004), many educators adopt published or commercially available reading programs, which lack empirical evidence of efficiency and effectiveness (Tobin \& Calhoon, 2009). In the UK, the additional support offered to children who encounter reading difficulty is often "Reading Recovery," a program that attempts to prevent educational failure by providing intensive instruction (i.e., several weeks of daily 30-min lessons, focusing on letter identification, word reading concepts, and text reading) to at-risk children. Shanahan and Barr (1995) reported that despite over 100 journal articles and conference presentations on Reading Recovery, claims of empirical evidence on effectiveness had been limited mainly to unpublished reports. They also observed that in order to avoid high costs of training, many schools develop their own models of Reading Recovery and these are also interventions not supported by empirical evidence.

There has recently been a great deal of interest in harnessing the motivational qualities of computer games in order to create engaging educational tools (Linehan, Kirman, Lawson, \& Chan, 2011). Computer-assisted instruction (CAI) includes specific computer applications in education such as simulation, drill, and practice and tutorials offered as independent activities or supplementary to general classroom instruction (Cotton, 1991). Analysis of 59 CAI studies found that CAI alongside conventional instruction produced better results than conventional instruction alone. Specifically, students learn material faster with CAI than conventional instruction alone, CAI is more beneficial for younger students than older students and lower achieving students than higher achieving students, students with specific learning difficulties achieve better results with CAI than with conventional instruction alone, and students' enjoyment of CAl is a direct result of the delivery of immediate feedback (Hall, Hughes, \& Filbert, 2000).

Aspects of CAI resemble instructional programs based on the principles of behavior analysis such as direct instruction (Watkins, 1988) and the personalized system of instruction (Kim \& Axelrod, 2005). Both approaches are typically delivered on a one-to-one basis, they set clear learning outcomes in individualized programs with high performance targets (typically $90 \%$ correct) that must be met to progress and corrective feedback is delivered based on each individual student's responses. In addition, Papert (1993) notes that computer programs teach children that learning can be fast paced, exciting, and rewarding, whereas classroom instruction can appear slow and boring by comparison. Given the motivational advantages of computer programs, many feel they should be used in an educational setting to encourage enjoyment of task acquisition (Boyle, 1997).

Headsprout( Early Reading and Comprehension ( ) is a CAI program designed by behavior analysts. It targets each of five subskills through intensive systematic phonics training. Headsprout $\subset$ claims to bring a beginning reader to a proficient level of reading in 80,20 -min, episodes, with an additional 50 episodes offered to target reading comprehension skills (Layng, Twyman, \& Stikeleather, 2003, 2004). The reading curriculum is broken down into parts, taught in a specific order without assuming background knowledge. Decisions to progress to the next stage of the curriculum are data-driven based on the performance in the previous stage of the curriculum. Headsprout $($ incorporates four key learning tactics. These are reduced errors (i.e., teaching begins at a very basic level and progresses slowly as the child performs correctly), a defined mastery criterion (i.e., no progress until the current material is mastered), guided practice (i.e., fluency as well as accuracy), and cumulative progress (see Grindle, Hughes, Saville, Huxley, \& Hastings, 2013). The presentation of each HeadsproutC episode provides a rich schedule of potentially reinforcing events (i.e., cartoons and praise for correct responses and access to video games for cumulative progress). 
A defining feature of Headsprout( is that it is individualized for every child to move at their own pace and if a child fails to master a particular task, that task is broken down into its component parts for the child in subsequent instruction. Outcome data show that HeadsproutC has been successful with typical learners (Twyman, Layng, \& Layng, 2011; Huffstetter, King, Onwuegbuzie, Schneider, \& Powell-Smith, 2010). Grindle et al. (2013) assessed its efficacy in teaching early reading skills to children with autism. Prestandardized and poststandardized reading tests determined that on completion of 80 episodes, the word recognition age (WRA) for all four children increased from 14 months to more than 3 years over 14 weeks of teaching. Follow-up tests showed that gains were maintained 8 weeks after the intervention ended.

The purpose of this study was to evaluate the efficacy of using Headsprout@ as a home-delivered supplementary program with a group not previously studied. These were children who had spent at least 1 year in care but were fully adopted at the time of the study and who were considered "at risk" of reading failure. The primary aim was to investigate whether using Headsprout(c) in their home setting no less than 4 times weekly would increase two key reading skills to above the at-risk boundary for their age and class level. Standardized tests of reading attainment were used to facilitate comparison of the findings with others conducted in UK educational settings. Due to differences in the skills of individual children at the start of the study, matched pairs were used to compare progress between treatment and comparison participants. The comparison child in each pair spent equal amounts of time with a researcher but engaged in other computer-based tasks. The comparison children received access to the intervention as soon as their treatment pair completed the program.

\section{2 | METHOD}

\section{1 | Participants}

Participants were three girls and five boys between the ages of 5 and 10. All of the children attended mainstream primary schools and were registered with Adoption UK, Belfast. Inclusion criteria were (a) full registration with Adoption UK, having spent at least a year in care prior to adoption; (b) ability to sit at a computer for a short time; (c) understanding and following at least two-step instructions; (d) English spoken as their first language; (e) ability to imitate spoken sounds and words; and ( $f$ ) a pretest score on the standardized reading test lower than the designated at-risk category for their age and school class level. Children were paired based on their age and class at school, and one child from each pair was randomly assigned to either the treatment (intervention) or comparison condition.

\section{2 | Setting}

Sessions were conducted 4 times per week in the child's home. Children were seated at a computer on a desk in a quiet area of their home. The first author and one parent were always present during the session but had minimal to no interaction with the child while they were engaged with Headsprout $\subset$ lessons. Children in the comparison condition were also visited 4 times weekly in their home setting where they completed online Mathematics tasks in order to control for computer use and time spent with the researcher.

\section{3 | Materials}

A desktop or laptop computer with internet access to Headsprout(C was used. Headsprout(C Early Reading consists of 80, 15- to 20-min, online episodes with printable "Sprout Stories" at the end of each episode. HeadsproutC Reading Comprehension consists of 50, 20-min, episodes. Reinforcement is provided within the program in the form of "gold coins," which can be traded in cartoons or games on the Headsprout $\subset$ website. Progress maps are also included in the program enabling children to "cross-off" each completed episode. On completion of every retest the researcher 
provided children with a snack of a preferred edible. All children involved in the study could communicate their preferences for food items effectively with the researcher.

\section{4 | Measures}

Pretreatment and posttreatment reading attainment scores and progress were monitored using two standardized reading attainment tests, the dynamic indicators of basic early literacy skills (DIBELS) 6th edition (Good \& Kaminski, 2002), and the word recognition and phonics skills set (WRAPS; Carver \& Moseley, 1994). The DIBELS assessment is a short 1-min fluency measure designed to identify children who are at risk of reading failure. Each child's total score on the assessment is the number of words read correctly from a passage in $1 \mathrm{~min}$. This is referred to as their oral reading fluency (ORF) score and is the measure of interest for this study. ORF is a particularly potent measure of successful reading as it encompasses phonological awareness and word recognition skills (taught explicitly in the Headsprout(C) Early Reading intervention) and word accuracy and fluency skills (the main area of focus in the Headsprout(C Reading Comprehension intervention). Thus, it was considered an appropriate measure for all age groups within the sample. The WRAPS assessment provides a standardized score and WRA for each child. The assessment requires that the child select the correct word out of an array of five words when the target word is presented in a sentence (e.g., "man," "an old man"). The child's total score is the number of correct words they can identify; this standardized score corresponds with a WRA.

\section{5 | Procedure}

The study adopted a repeated measures design. The DIBELS and WRAPS were administered to all children prior to the intervention and children were placed in matched pairs based on the grade level material with which they were assessed and chronological age. One child from each pair was randomly assigned to either treatment or comparison conditions. Standardized tests were readministered with both children in each pair after completion of every 20 lessons by children using Headsprout (C) Early Reading or after completion of 25 lessons or episodes by children using Headsprout ( Reading Comprehension. The final posttreatment tests were conducted immediately on completion of episode 80 with both children in each pair for children using Headsprout $\subset$ Early Reading or after completion of lesson 50 by children using Headsprout(c) Reading Comprehension. Total intervention time for all participants ranged from 4 to 5 months.

The procedure adopted was similar to that of Layng et al. (2004) for typically developing learners. Following pretesting and random allocation into either treatment or comparison groups, children were assigned to either Headsprout(c) Early Reading or Headsprout(c) Reading Comprehension. This decision was made based on the participants' ages and is consistent with the recommended guidelines from the company for use of this program. Participant pairs A and B, comprised of for children (two treatments and two controls) ranging from ages 9 to 10 used Headsprout(C Reading Comprehension, and pairs C and D, ages 7-8, were assigned the Headsprout $($ Early Reading program.

The first lesson for each child in the treatment group ensured that each child had the prerequisite computer skills necessary to engage fully with the program. This offered children the opportunity to become familiarized with Headsprout's typical instructions and practice basic computer skills such as dragging and clicking. During lessons, the first author initially sat directly beside each child and prompted only with "Speak out loud" and "Listen to your Headsprout", for any off-task behavior. As children became more independent in using the program she sat directly behind the participant and issued the same two prompts only when required. Progress data were recorded automatically by Headsprout $($ ), which does not allow children to progress to the next episode until they reach a $90 \%$ mastery criterion. At the end of each episode, students immediately read the printable Sprout Stories book from their computer screen. This revised the skills that they learned during their HeadsproutC episode and correct responses were prompted by the researcher if a child failed to recognize a particular word. 
Children completed a minimum of four Headsprout(c) episodes per week and no more than one episode per day. The first author was present for each of the four episodes. The comparison children were visited (where possible) on the same days as their treatment partners and engaged in 20 min of computer time completing basic math activities using the online IXL Mathematics program.

\subsection{Data collection and reliability}

Data for correct responding, errors made, and episode completion time were automatically collected by the HeadsproutC program. The two measures of interest for the researcher (ORF and WRA) were calculated directly by the researchers using the DIBELS and WRAPS assessments throughout the treatment period and pretreatment and posttreatment scores for both measures were compared. To calculate interobserver agreement (IOA) on assessment scores, the second author also observed and recorded participants' responses during assessments using both measures at pretest and posttreatment points. IOA was calculated by dividing the number of observer agreements by the number of judgements. IOA was above $95 \%$ for all pretreatment and posttreatment assessments across all participants. The first researcher also kept a session diary of any off-task behavior or notable environmental changes during each visit. However, no additional instruction was required for any participant throughout the duration of the intervention nor were there any instances of challenging behavior or resistance to completing the episodes.

\section{3 | RESULTS}

As in Grindle et al. (2013), data were analyzed for changes in each individual child's ORF score and WRA over the course of the intervention and compared across treatment and comparison pairs. Scores across both measures were standardized according to each child's chronological age. Table 1 displays the standardized ORF scores for each treatment participants and their matched comparison pair at pretest, a midpoint check (episode 25 for HeadsproutC) Reading Comprehension or HRC participants and episode 40 for Headsprout(C Early Reading or HER participants) and at posttreatment. The table also shows the standardized at-risk boundary for each child dependent on the grade level material with which they were assessed. For the treatment children, ORF scores all increased from pretest to midpoint and again from midpoint to posttreatment, and for three of four children, the scores moved from below to above the at-risk boundary. For the comparison children, there was an increase in 1 of 4 from pretest to midpoint and zero out of four from midpoint to posttreatment. All of the comparison children stayed below the at-risk boundary.

Table 2 shows the changes in WRA from pretest to posttreatment (duration of 4 months) for each child. All treatment participants increased their scores, by 3 months, 6 months, 6 months, and 2 years, and comparison

TABLE 1 Standardized ORF scores at pretest, midpoint, and posttreatment, and the "at-risk" boundary scores, for treatment (HRC or HER) and comparison children

\begin{tabular}{|c|c|c|c|c|c|c|}
\hline Name & Age & Group & Pretest & Midpoint check & Posttreatment & Grade level "at-risk" boundary \\
\hline Julie & 9.5 & HRC & 52 & 90 & 96 & 70 \\
\hline Christopher & 9.7 & Comparison & 52 & 52 & 52 & 70 \\
\hline Simon & 9.8 & HRC & 51 & 63 & 79 & 70 \\
\hline Peter & 9.4 & Comparison & 54 & 73 & 47 & 70 \\
\hline Neil & 7.7 & HER & 36 & 43 & 49 & 53 \\
\hline Jennifer & 7.5 & Comparison & 56 & 47 & 49 & 53 \\
\hline Karen & 7.1 & HER & 21 & 41 & 45 & 37 \\
\hline Gary & 7.0 & Comparison & 6 & 2 & 2 & 37 \\
\hline
\end{tabular}

Note. $\mathrm{ORF}=$ oral reading fluency. 
TABLE 2 WRA (in years and months) posttreatment for treatment (HRC or HER) and comparison children at pretest and posttreatment

\begin{tabular}{lllcr} 
Name & Age & Group & Pretest & Posttreatment \\
\hline Julie & 9.5 & HRC & 8.6 & 8.9 \\
Chris & 9.7 & Comparison & 8.9 & 8.6 \\
Simon & 9.8 & HRC & 6.8 & 7.4 \\
Peter & 9.4 & Comparison & 8.6 & 7.9 \\
\hline Neil & 7.7 & HER & 6.8 & 7.4 \\
Jennifer & 7.5 & Comparison & 6.8 & 7.3 \\
Karen & 7.1 & HER & 5.9 & 7.9 \\
Gary & 7.0 & Comparison & 5.6 & 5.6 \\
\hline
\end{tabular}

Note. WRA = word recognition age.

children's scores fell in cases (by 3 or 7 months) or stayed the same or increased (by 5 months). Figure 1 displays the mean group differences between ORF scores and WRA from pretest to posttreatment. Across both measures, the treatment group improved across the 4-month intervention period, whereas the control group experienced a decline in this time. On average, treatment participants improved by 27 words per minute in the ORF assessment (Figure 1 top panel) and 13 months in WRA (Figure 1 bottom panel) from pretreatment to posttreatment. In contrast, the control participants experienced an average decline in ORF of five words per minute and a 1-month decline in WRA.

\section{4 | DISCUSSION}

In this study, children who received the Headsprout(C) intervention made greater gains on two measures of reading than paired comparisons. In three out of four treatment participants, posttreatment ORF scores were above the atrisk boundary for their grade level (Grindle et al., 2013). Given the relatively short time span, the results for each of the four children are encouraging, particularly when compared to paired children. Across all participant pairs, comparison participants' ORF and WRA scores either decreased or showed no age-related increase. Given that the study was carried out from March to July while participants were attending school, this finding suggests that their regular literacy lessons in school were not having a significant impact on their literacy skills. This supports the claim that without specific literacy intervention, the attainment gap between children who have been in care and their peers will grow as their school work increases in difficulty. In addition, this also suggests that for adopted children, placement in a stable familial environment does not necessarily eradicate the risk of educational failure due to reading difficulty (Cairns, 2002).

Although the findings present a promising platform upon which to build an evidence base for use of Headsprout ( with this population, there are significant limitations to this study. The use of a group-design methodology with a small number of participants limits the generalization of these findings to a larger sample of individuals within this societal group. Recruitment from this particular population proved difficult. Some parents registered with the agency through which the children were recruited stated that they recognized the need to address this issue but felt that the program being delivered relatively intensively within their home could perhaps disrupt their child's "settling in" period in their new home.

The group design also posed threats to internal validity which is evident in the case of comparison participant Peter. He displayed increases in ORF during the first 6 weeks of the intervention. However, it was later discovered that upon commencement of this study, he also received an intensive 6-week literacy program that was being pioneered in his school at that time. Adopting a multiple-baseline design and obtaining repeated measures of ORF across a 4-month period would have ensured a stronger demonstration of experimental control within the study. 

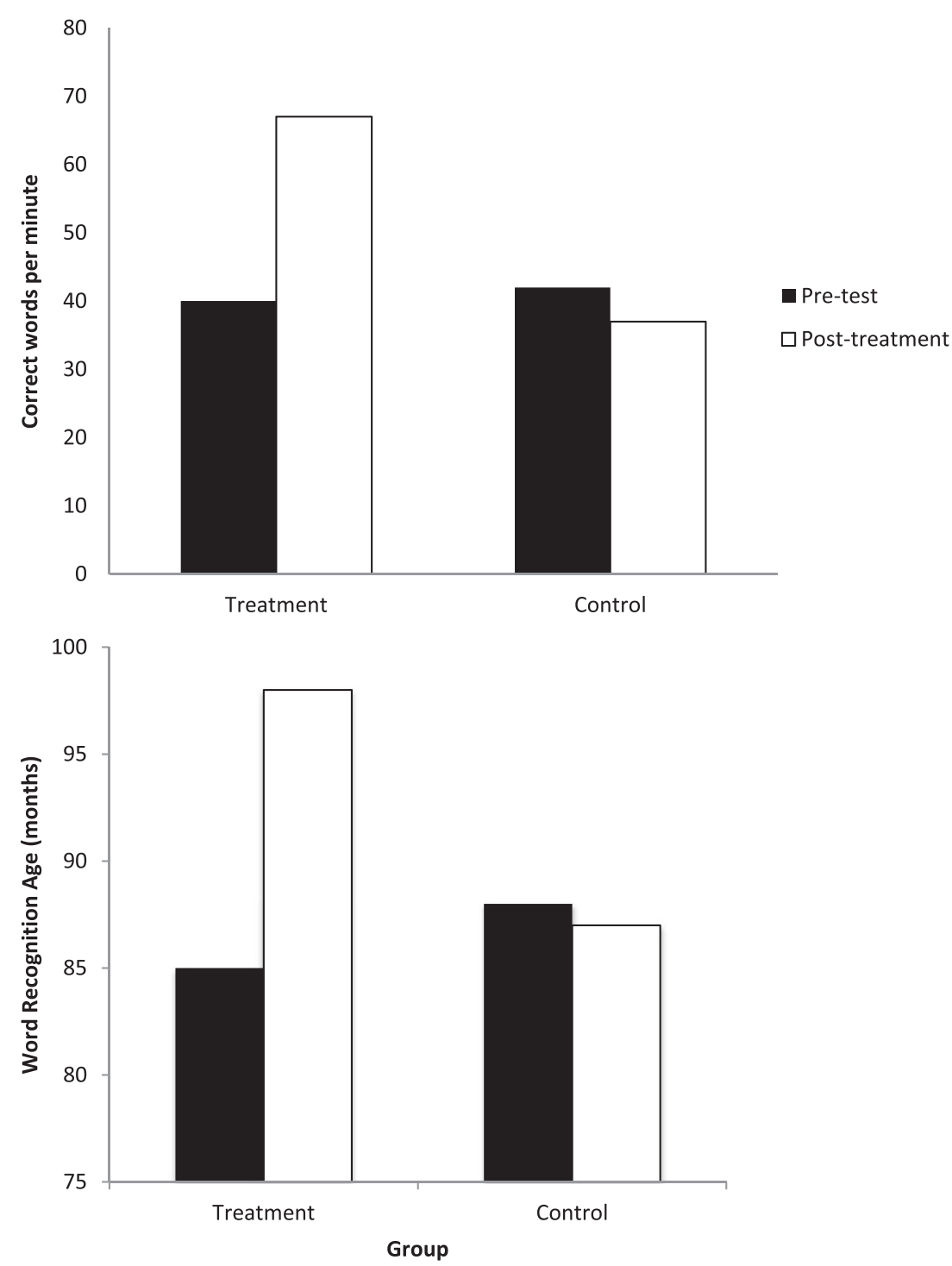

FIGURE 1 Mean oral reading fluency scores (top panel) and mean word recognition age scores (bottom panel) for treatment and comparison participants at pretest and posttreatment

The difficulty in adopting this approach lay with the tradition of experimental research within educational studies. Three common research designs used are between-subjects, within-subjects, and factorial designs, whereby the dependent measure is the change in performance scores between randomly assigned groups from the beginning of an academic year to the end or from the beginning of one semester to the next. The standardized educational attainment tests typically used to support these designs are comprised of two parts, the first intended for pretest and the second for posttest. This was the case for the standardized measures used within this study, which were employed to facilitate comparison with other educational research findings. In order to meet the requirements of a multiple-baseline design, each child would have been repeatedly exposed to the same two assessments (the pretest and posttest) potentially resulting in rote learning of the test material; thus, there were not sufficient resources to carry out a multiple-baseline design. The Headsprout $\odot$ program is built upon behavior analytic principles, which need to be more widely utilized within the UK education system. However, it was thought that applying an educational 
experimental design with this behavioral intervention may be beneficial in increasing the accessibility of behavioral approaches to parents and educators.

Although treatment participants outperformed their comparison pairs in the WRA, improvement in this skill is considered clinically significant only with an improvement of 14 months to 3 years over 14 weeks of teaching (Grindle et al., 2013). The only participant to exceed this 14-month increase in WRA was Karen (24 months) and she was also the only participant with a posttreatment WRA greater than her chronological age. Findings for this measure should be approached, however, with caution. The WRAPS assessment used in this study provided a standardized score of word recognition that corresponded to a specific WRA. However, the use of the age-equivalent scores has been criticized for encouraging the use of false standards (Sattler, 2001). Individual differences between students within a grade can result in a range of achievement that spans several grade levels; thus, a second-grade teacher should not expect that all students will perform on a literacy test at the second-grade level. Children may perform at the first-grade level on a reading test but at the third-grade level on a writing test. Therefore, it can be dangerous to use age and grade equivalents as standards of performance. Despite this, age equivalent scores can be easily interpreted by parents and teachers and can place the performance of their children and students within a context. In this instance, age equivalent scores were used to promote the accessibility of behavioral interventions within an educational context.

Despite its limitations, this report has shown Headsprout's $($ promise for addressing the instructional deficits of a population of children who must be brought to the attention of researchers and educators within this area. In order to state with increased confidence that Headsprout(C is an effective supplementary tool for increasing literacy skills, future research should demonstrate much stricter experimental control. To further enhance the case for Headsprout $\odot$, its efficacy could be compared with another literacy intervention. Evaluations of this kind of intervention are essential for parents and educators to use evidence-based practices with their children and students, and in the UK in particular, behavioral approaches should be made more accessible to the education system.

\section{REFERENCES}

Boyle, T. (1997). Design for multimedia learning. Hertfordshire, UK: Prentice Hall Europe.

Cairns, K. (2002). Attachment, trauma and resilience. London, UK: British Association for Adoption and Fostering.

Carver, C., \& Moseley, D. (1994). Group or individual diagnostic test of word recognition and phonic skills (WRAPS). London: Hodder Arnold.

Cotton, K. (1991). Computer-assisted instruction. Northwest Regional educational laboratory school improvement research series (SIRS). Retrieved April 20th 2015 from http://www.nwrel.org/scpd/sirs/5/cu10.html.

Dann, R. (2011). Look out! "Looked after"! Look here! Supporting "looked after" and adopted children in the primary classroom. Education 3-13:International Journal of Primary, Elementary and Early Years Education, 39(5), 455-465. doi:10.1080/03004279.2010.488069

Davidson, M., \& Jenkins, J. (1994). Effects of phonemic processes on word reading and spelling. The Journal of Educational Research, 87, 148-157. doi:10.1080/00220671.1994.9941236

Department for Education and Employment (DfEE) (1999). Improving Literacy and numeracy: A Fresh Start. The Report of the Working Group Chaired by Sir Claus Moser (London). Retrieved July 15th, 2015 from http://www.lifelonglearning.co.uk/ mosergroup/

Department of Education (2012). Statistical First Release. Outcomes for Children Looked After by Local Authorities in England, as at 31st March, 2012. Retrieved April 20th 2015 from https://www.gov.uk/government/uploads/system/uploads/attachment_data/file/191969/SFR32_2012Text.pdf

Francis, D. J., Shaywitz, S. E., Stuebing, K. K., Shaywitz, B. A., \& Fletcher, J. M. (1996). Developmental lag versus deficit models of reading disability: A longitudinal, individual growth curves analysis. Journal of Educational Psychology, 88(1), 3. doi:10.1037/0022-0663.88.1.3

Good, R. H., \& Kaminski, R. A. (2002). DIBELS oral reading fluency passages for first through third grades. Technical report 10. Portland Oregon: University of Oregon.

Grindle, C. F., Hughes, C. J., Saville, M., Huxley, K., \& Hastings, R. P. (2013). Teaching early reading skills to children with autism using Mimiosprout early reading. Behavioral Interventions, 28(3), 203-224. doi:10.1002/bin.1364 
Hall, T. E., Hughes, C. A., \& Filbert, M. (2000). Computer assisted instruction in reading for students with learning disabilities: A research synthesis. Education and Treatment of Children, 23, 173-193. Retrieved April 18th 2015 from http://www. jstor.org/stable/42940524?seq=1\#page_scan_tab_contents.

Huffstetter, M., King, J. R., Onwuegbuzie, A. J., Schneider, J. J., \& Powell-Smith, K. A. (2010). Effects of a computer-based early reading program on the early reading and oral language skills of at-risk preschool children. Journal of Education for Students Placed at Risk, 15, 279-298.

Johnston, R. S., \& Watson, J. E. (2004). Accelerating the development of reading, spelling and phonemic awareness skills in initial readers. Reading and Writing, 17, 327-357. doi:10.1023/B:READ.0000032666.66359.62

Kim, T., \& Axelrod, S. (2005). Direct instruction: An educators' guide and a plea for action. The Behavior Analyst Today, 6 , 111-120. doi:10.1037/h0100061.Behavior Analyst Today, Vol 6(2), 2005, 111-120.

Layng, J., Twyman, J., \& Stikeleather, G. (2003). Headsprout early reading: Reliably teaching children to read. Behavioral Technology Today, 3, 7-20. Retrieved June 19th 2015 from http://behavior.org/httpdocs/resources/191.pdf.

Layng, J., Twyman, J., \& Stikeleather, G. (2004). Selected for success: How Headsprout reading basics teaches beginning reading. In D. J. Moran, \& R. W. Malott (Eds.), Evidence-based educational methods. (pp. 171-197). San Diego: Elsevier Academic Press.

Linehan, C., Kirman, B., Lawson, S., \& Chan, G. (2011). Practical, appropriate, empirically-validated guidelines for designing educational games. Proceedings of the 2011 annual conference on Human factors in computing systems- CHI'11. ACM, New York, NY, USA.

Papert, S. (1993). The Children's Machine: Rethinking school in the age of the computer. New York, NY, USA: Basic Books, inc.

Sattler, J. M. (2001). Assessment of Children: Cognitive Applications. San Diego, CA: Sattler Publisher.

Shanahan, T., \& Barr, R. (1995). Reading recovery: An independent evaluation of the effects of an early intervention for at-risk learners. Reading Research Quarterly, 30, 958-997. Retrieved July 15th 2015 from ProQuest database.

Tobin, K. G., \& Calhoon, M. B. (2009). A comparison of two reading programs on the reading outcomes of first-grade students. Journal of Direct Instruction, 9, 35-46. Retrieved August 15th, 2015, from PubMedCentral database.

Twyman, J., Layng, J., \& Layng, Z. (2011). The likelihood of instructionally beneficial, trivial, or negative results for kindergarten and first grade learners who complete at least half of Headsprout early reading. Behavioral Technology Today, 6, 1-13. Retrieved April 20th, 2015 from http://behavior.org/httpdocs/resources/519.pdf.

Watkins, C. L. (1988). Project follow through: A story of the identification and neglect of effective instruction. Youth and Policy, 10(1), 7-11 Retrieved May 18th, 2015, from ProQuest database.

How to cite this article: Storey C, McDowell C, Leslie JC. Evaluating the efficacy of the HeadsproutC reading program with children who have spent time in care. Behavioral Interventions. 2017;32:285-293. https://doi. org/10.1002/bin.1476 